\title{
LA LECTURA EN ESPACIOS PÚBLICOS DE SANTIAGO
}

\author{
Alberto Mayol
}




\section{ALBERTO MAYOL}

Sociólogo y Magíster en Ciencia Política de la Universidad de Chile. Licenciado en Estética de la Pontificia Universidad Católica de Chile, DEA en Teoría Sociológica de la Universidad Complutense de Madrid y candidato a Doctor en Teoría Sociológica de la misma Universidad. Académico de la Universidad de Chile. Investigador y Director de la Línea de Economía y Política del Laboratorio Transdisciplinar en Prácticas Sociales y Subjetividad de la Universidad de Chile. Es miembro del Consejo del Observatorio del Libro y la Lectura. Investigador responsable del proyecto "La lectura como práctica social". 


\title{
LA LECTURA EN ESPACIOS PÚBLICOS DE SANTIAGO
}

\author{
Alberto Mayol ${ }^{1}$, Carla Azócar², Isidora Vásquez ${ }^{3}$
}

\section{INTRODUCCIÓN}

En el marco de una investigación sobre las condiciones de institucionalización de la lectura como práctica cultural ${ }^{4}$, se examinaron parques, recorridos de Transantiago (troncales y alimentadores), líneas de Metro, salas de esperas de casas comerciales, de servicios de salud y de bancos, bibliotecas, centros comerciales, recorridos de Metrotren y de buses interurbanos, paraderos, museos, cafeterías y librerías. El proyecto había nacido para comprender la relación de la lectura y los libros con la vida cotidiana, tratando de entender cómo la actividad de leer se relaciona con los tiempos y espacios de los ciudadanos. Una dimensión de esa relación es la que aquí abordamos: la lectura y el espacio público urbano, específicamente en la ciudad de Santiago. La investigación está compuesta por diversos informes de variadas perspectivas y metodologías ${ }^{5}$, pero nos ha parecido interesante concentrar la mirada en lo que está aconteciendo en las calles.

A partir de estas 200 horas de observación llevadas a cabo por un equipo de etnógrafas y etnógrafos de la Universidad de Chile, obtuvimos un panorama sobre las actividades que las personas desarrollan en ellos y cómo se inscriben actividades culturales y específicamente la lectura.

Nuestro interés es la lectura no-obligatoria, que se desarrolla por motivos más cercanos a la curiosidad, la entretención, el placer, la belleza, es decir la lectura que se inscribe en el marco de actividades de ocio, o hedonistas si se quiere, en tanto no está orientada a reportar beneficios materiales ni sociales específicos, como el prestigio, el desarrollo laboral, el consumo, o en definitiva la adaptación social. Esta lectura ociosa es la que entendemos fundamental para la mantención del hábito de la lectura en general y es, a la vez, la que vemos críticamente amenazada en nuestra sociedad. Por supuesto, nuestra observación no discriminó la lectura obligatoria, pero se considera ella un telón de fondo sobre el cual la práctica voluntaria es decisiva. De alguna manera, durante la investigación fuimos definiendo la necesidad de distinguir entre la lectura obligatoria,

1. Investigador responsable del proyecto "La lectura como práctica social". Académico Universidad de Chile y Universidad de Santiago de Chile.

2. Investigadora y coordinadora del proyecto "La lectura como práctica social". Licenciada en Antropología Social de la Universidad de Chile. Ayudante de Investigación en el Centro de Investigación en Estructura Social.

3. Investigadora y encargada de interpretación etnográfica del proyecto "La lectura como práctica social"

4. "La lectura como práctica social: Condiciones de fortalecimiento y debilitamiento de la lectura", folio 8756. Fondo del Libro - Investigación 2013 - Modalidad única.

5. Para revisar dichos informes y materiales, están disponibles numerosos documentos relevantes del estudio en http://www.albertomayol.cl/?page_id=310 
la lectura instrumental y la lectura ociosa. Los límites de estos conceptos guardan en su seno algunas deficiencias, pero son un avance indispensable a nuestro juicio. La lectura obligatoria está asociada a exigencias laborales o estudiantiles que son de carácter perentorio. Si el nuevo trabajo supone trabajar con un nuevo sistema operativo, un nuevo procesador de datos, si supone revisar el manual mecánico de una máquina (automóvil, avión), por ejemplo, evidentemente estamos frente a la lectura obligatoria. Por otro lado, mucho más difusa, se encuentra la lectura instrumental. Se trata de una cultura que supone un aprendizaje concreto o cuyo aprendizaje genérico se enmarca en el esfuerzo de generar un rendimiento futuro de corte utilitario. La lectura pasa a ser portadora de un recurso, de un capital, útil para desenvolverse en actividades específicas que generan alguna clase de rendimiento en esa expectativa normativa fundamental de las sociedades contemporáneas que es el éxito (tener dinero, fama, poder, básicamente) o al menos en la mitigación del fracaso y la soledad (lo que ejecutan los libros de autoayuda). Finalmente, la lectura por ocio es aquella que definimos como mera lectura por la lectura, basada en el placer, la satisfacción de necesidades espirituales o el pasatiempo

Esta distinción tiene un inconveniente. La principal característica de la lectura es su atributo como práctica capaz de cultivar capacidades, perspectivas, emociones y despertar la inquietud y el asombro intelectual. Su carácter acumulativo y el creciente placer del refinamiento son sus atributos fundamentales, aunque se puede leer también la lectura como la capacidad de consolidar y potenciar aprendizajes anteriores. Desde cierta perspectiva, muy afín con las visiones propias de la teoría de la libre elección, este aumento de competencias es visto como una actividad instrumental, útil. Sin embargo, aunque no es falso que entre los rasgos importantes de la lectura está la utilidad, no es menos cierto que es muy distinto "cultivarse" con respecto a "capacitarse" 6 . Es decir, es importante distinguir entre la consecuencia y la motivación. No es lo mismo que una actividad lectora redunde en mayores capacidades como resultado de su ejercicio, que ejecutar dicha actividad para obtener resultados específicos (de hecho, la búsqueda utilitaria no está buscando conseguir mayores capacidades, sino los efectos que ella puede procurar).

Nuestras observaciones en general nos revelan que la práctica de la lectura en la intimidad del hogar se encuentra en una crisis de gran magnitud. En cambio, la lectura en espacios públicos se presenta como un espacio de resistencia de la lectura ante su declive e incluso como un espacio donde se detectan algunas fortalezas. Esto es llamativo y permite prologar los resultados más específicos de las observaciones.

\section{OBSERVACIONES SOBRE LOS ESPACIOS PÚBLICOS}

La mayor parte de los espacios públicos de Santiago son lugares de paso. Se trata de espacios de circulación, transporte, espera entre un destino y otro. Una ciudad compleja,

6. Esto ha sido investigado en Mayol, A., Azócar, Carla y Azócar, Carlos, El Chile Profundo, Santiago: Liberalia, 2013. 
de gran tamaño, densidad vehicular y con problemas en el sistema de transporte, se traduce en una ciudad con numerosos espacios y tiempos de corte intersticial entre un lugar específico y otro. A este rasgo debemos sumar la escasa característica de "lugar" de estos espacios de paso, es decir, se trata en general de espacios que no ofrecen soportes efectivos para que suceda otra cosa. Lo que encontramos en cambio, son diseños y arquitecturas para no-actividades, acordes a estos — también llamados- no-lugares. No se desarrolla en ellos actividades que devengan significativas ni conscientes, como el trabajo, el deporte, el juego, el encuentro social, la integración cultural, etc. Lo que encontramos, más bien, es justamente un espacio relativamente vacío de sociedad. Y es que gente que pasa no es lo mismo que grupos o comunidades.

Este vacío, sin embargo, nos indica la presencia y acción de otro actor: el consumo. En la mayoría de los espacios públicos, la acepción de lo "público" que toma centralidad, es más bien la de "conjunto de personas que asiste a un espectáculo", es decir, un espacio que propicia la generación de una audiencia receptiva de mensajes; y no la de un "espacio común y perteneciente al pueblo" (como define la RAE). En otras palabras, estos espacios operan más bien como escenario o vitrina, que entrega una multitud de contenidos a quienes los transitan, y que sin embargo con ello obstaculiza otras maneras de hacer de ellos verdaderos lugares públicos.

El origen de la calle moderna (he aquí la observación de Baudelaire y de Benjamin leyendo Baudelaire) es el espectáculo del sí mismo, la presentación en sociedad, ya no en el salón o la recepción, sino en la calle misma, en el boulevard, donde los cafés de organizan mirando hacia la calle para mirar, juzgar y comentar a la gente que por ahí transita. Esta ciudad es el correlato acrítico de la ciudad bohemia, es la norma de una sociedad que ha desarrollado el gusto y la puesta en escena de sí mismo. Pero la calle neoliberal es diferente: la puesta en escena es del bien de consumo, el objeto en venta, no el ciudadano. El objeto admirado no es el individuo libre que pasea por la calle demostrando la existencia del recientemente conquistado (por algunos) ocio y de su buen gusto. El objeto admirado es el producto generado a bajo costo en un país pobre y lejano y vendido a gran valor por una marca reconocida en una metrópoli. También la ciudad neoliberal debe permitir demostrar los principales logros del individuo de esta sociedad: su capacidad de consumo y su capacidad de fluir por las distintas dimensiones de lo social. La fluidez $z^{7}$ es la capacidad de contar con un estilo de vida que carece de roce, fronteras, límites, es el ciudadano del dejar hacer, dejar pasar: indiferente, indulgente, impune, relajado, pero fundamentalmente capaz de armonizar esto con rapidez, poder, éxito, entre otros rasgos que plantean la resolución de una paradoja.

Sin embargo, y junto con ofrecer un marco tan específico para el desarrollo de estas no-actividades (como el vitrineo inconsciente, hablar por celular, escuchar música, escribir mensajes de texto y conectarse a las redes sociales en dispositivos portátiles, etc., todo mientras se camina o se espera), fue posible encontrarnos con la lectura noobligatoria. Se desarrolla generalmente en espacios un poco más protegidos de este carácter publicitario, pero muchas veces en competencia con él.

7. Concepto desarrollado en Mayol, A., "El derrumbe del modelo", Santiago: LOM Ediciones, 2012. 
Sabemos que la lectura de ocio ha perdido su espacio en la vida cotidiana, cediendo sus lugares tradicionales; en el hogar, las tardes, las noches y los fines de semana, todos espacios que han sido colonizados por prácticas de consumo y otras formas de enajenación del tiempo, como la televisión y las redes sociales virtuales. En este sentido podemos afirmar que el lugar de la lectura hoy en nuestra sociedad es en general el de la marginalidad. En otras palabras, la lectura se ha desplazado a los rincones y bordes de la rutina.

De esta manera, no es raro encontrarla en las pequeñas grietas de la vida cotidiana, en donde no le quite realmente espacio ni tiempo a nada relevante. Hemos constatado que estas grietas suceden en los espacios públicos. Gran parte de los lectores y las lectoras que encontramos en estos espacios, son quienes no están leyendo en sus casas. Y asimismo, vemos que quienes sí leen por ocio, sistemática y frecuentemente, suelen darle más protagonismo a la lectura, desarrollándola principalmente en sus casas y dormitorios, en vez de en los espacios públicos. Las y los lectores en espacios públicos son personas que leen, y probablemente —esta es nuestra apuesta - hay otras personas que como ellas, leerían en estos espacios "de paso" si se ofrecieran las condiciones para eso.

Ahora bien ¿qué tipo de lectura es la que sucede en estos espacios? Generalmente es de baja concentración, siempre vulnerable a interrupciones. Por otro lado es una lectura que se hace en los intersticios de la jornada laboral, es decir entre las 07:00 y las 18:00 horas, nunca después del trabajo. El cansancio cede protagonismo a otras maneras de pasar el rato, que requieren menor concentración y compromiso.

Nos encontramos entonces, con una lectura de ocio intersticial; una lectura que se ve fuertemente amenazada y que es escasa, pero que sin embargo parece tener su pequeño y quizás propio lugar en el espacio público. Un lugar que nos parece fundamental considerar a la hora de pensar en el fomento a la lectura.

Cada espacio tiene su propio carácter, dependiendo incluso del momento en el que se observe. Sin embargo, algunos rasgos comunes aparecieron como críticos a la hora de comprender el escenario en que se desarrolla (o no) la lectura por ocio.

\section{a) Publicidad}

Si bien no es novedad para ningún habitante de Santiago que existe una saturación visual —liderada por avisos publicitarios, y secundada por la propaganda electoral del momento-, es relevante constatar el efecto que esto acarrea en específico para el desarrollo de la lectura en general en espacios públicos.

Casi la totalidad de los espacios públicos (exceptuando plazas y parques) están configurados por pantallas gigantes, afiches y carteles publicitarios, cubriendo fachadas y muros completos, e incluso el suelo. La dificultad de esto es que al ser propagandas (ya sea para promocionar productos o personas) justamente atraen la vista y la atención, y con ello, si bien no impiden, sí obstaculizan permanentemente el desarrollo de cualquier actividad que requiera concentración.

En otras palabras, estos espacios, al estar predominantemente marcados como espacios publicitarios, terminan haciendo que las prácticas que no respondan a ese registro, 
el del consumo, queden excluidas; actividades como la lectura, no le pertenecen, no le corresponden, y resultan exóticas al desarrollarse allí, fuera de lugar.

De cualquier modo, la publicidad nos conduce a una temática que tendrá relevancia en análisis posteriores, que trata sobre el exceso de estímulos como un problema en sí mismo para desarrollar la lectura.

\section{b) Gran escala}

Los espacios públicos de nuestra capital tienden a configurarse a gran escala. Sus dimensiones frecuentemente dibujan espacios amplios, abiertos, techos altos, mucho espacio libre, explanadas, entre otros. Por ejemplo: al interior y en las afueras de ciertas estaciones de metro, en los centros comerciales y sus patios de comidas, en el zócalo del GAM, etc. En el marco de nuestras observaciones, encontramos que estas condiciones del espacio dificultan la lectura. La lectura parece requerir un cobijo en el espacio público. Y aunque la amplitud es importante, básicamente porque la sensación de estar confinado es una clara amenaza, no es menos cierto que el exceso de tamaño, la pérdida de protagonismo del individuo en la sociedad o en la arquitectura urbana, reduce a una insignificancia donde el potencial cultural parece perderse. El individuo necesita sentirse suficientemente pequeño para sentirse en expansión respecto al espacio que lo cobija, pero también requiere sentirse suficientemente grande para ser visible, relevante, olímpico en su encierro. La soledad de la lectura debe tener un rasgo de elevación, no de anomia.

\section{c) Naturaleza: plazas y parques}

La lectura parece rehuir la "escenografía de masas" y en cambio se encuentra en la naturaleza (plazas y parques) un buen espacio para existir. Nuestras observaciones revelan que cuando convergen ciertas características en un espacio, la lectura tiende a aparecer. Cuando hay sombra, algo de ventilación, no hace frío (o no demasiado), no hay lluvia y el espacio público tiene algún rasgo de cobijo; es muy probable que alguien se haya situado en ese lugar para leer.

Las plazas y parques de la capital son los espacios públicos que más albergan actividades de ocio. Las actividades principales varían, pero en la mayoría hay personas "pasando el rato", ya sea conversando en grupos, almorzando, paseando en familia, haciendo deporte, y también leyendo.

Sus rasgos comunes, y que hemos constatado como fundamentales para el desarrollo de este tipo de actividades de ocio, son: ofrecer un espacio visual libre de publicidad, y ofrecer sombra. Hemos visto ya el efecto de la publicidad en otros espacios públicos y su capacidad para intervenir en el tipo de actividades que se realizan allí. La sombra sin embargo apareció como un factor central a la hora de facilitar espacios de lectura en la ciudad. 
Cabe señalar que las plazas y parques de la capital ofrecen condiciones muy diferentes entre sí. Parques como la Quinta Normal, el parque de Los Reyes, parque Forestal y la Plaza de Armas, se distinguen enormemente de las plazas de barrio, y también de parques como el Uruguay y el Bicentenario. Su arborización, la articulación de espacios de flujo y de apostamiento, así como su ubicación, son factores claves para facilitar y dificultar diferentes usos.

Por ejemplo, los parques y plazas más "jóvenes" poseen menor follaje y por ende menos sombra, lo que en primavera y verano dificulta la mayoría de sus usos, pasando a ser espacios de ornamentación principalmente. Lo mismo sucede en plazas y parques adyacentes a grandes arterias vehiculares, sobre todo si no poseen buena aislación vegetal del entorno, pasan a ser espacios decorativos meramente, o de colación como en el caso del parque Uruguay. Por otro lado, influye enormemente en el uso de plazas y parques, los edificios y servicios que se encuentren en sus alrededores, en tanto estos indirectamente generan disposiciones de uso del espacio (por ejemplo de ocio, productivo, de consumo, etc.).

Habiendo constatado que en las estaciones cálidas, plazas y parques ofrecen un espacio único de albergue a actividades de ocio, esparcimiento e integración cultural, como la lectura, es preocupante el panorama para la otra mitad del año. Durante el otoño e invierno estos espacios son incapaces de ofrecer lugares de refugio $y$, al no haber alternativas que reúnan condiciones similares, estas actividades quedarían virtualmente desamparadas ${ }^{8}$.

\section{d) Vagones}

El Metro y el Metrotren ofrecen resultados de lectura que no se encuentran en otros medios de transporte público como los buses interurbanos y de Transantiago. Hemos constatado que estos espacios de transporte (los vagones de Metro y de Metrotren) albergan incluso más lectura de ocio que cafeterías y bibliotecas.

Por una parte, la regularidad del recorrido, es decir que el tren se detenga en intervalos bastante predecibles, y que por tanto se demore siempre lo mismo de inicio a destino, hacen que sea posible concentrarse en la lectura de libros con mayor facilidad, sin necesidad de estar alerta constantemente al entorno. Esto es importante pues refiere a una de las conclusiones más interesantes del estudio: cuando la situación es "expectante", cuando hay una necesidad de "acecho" o, lo que es lo mismo, cuando la persona se encuentra en una situación "de cacería" no puede haber lectura. Hemos denominado como situación "de cacería" aquella que refiere a los momentos en que las personas se encuentran en espacios públicos donde se requiere cierta atención para ganar un espacio o para no perderlo. Es así como en las consultas médicas, oficinas de empresas masivas, la lectura no es habitual, a menos que sea a modo de hojear algo (un periódico gratuito con frecuencia, de textos cortos). Parece temerse, no sin fundamento, que una

8. Más adelante veremos cómo las cafeterías y bibliotecas, que serían los espacios públicos a recurrir en las estaciones más frías, no se presentan como espacios alternativos. 
leve desconcentración pudiera implicar perder el lugar asignado en la espera. En el caso del andén de Metro aparece un caso similar, donde el problema es no poder ganar una ubicación mejor o definitivamente poder incluso perder el turno. El resultado es que, siendo un espacio viable, no se lee.

Lo cierto es que en los vagones de servicios ferroviarios hay lectura. Esto no sucede en los buses, dado que la circulación por calles y avenidas ofrece usualmente una importante cuota de novedad, ya sea el tráfico vehicular, accidentes, arreglos en la vía, entre una infinidad de estímulos, que hacen menos regular el recorrido y por ende mayor la necesidad de estar atento al entorno. Aparece aquí algo ya referido: un exceso de estimulación alrededor reduce la lectura.

Luego, la regularidad que dan los rieles al recorrido del tren se expresa también en que la sensación de movimiento en los vagones sea mínima. Salvo excepciones, los vagones no oscilan ni frenan abruptamente, por lo que se facilita la lectura concentrada por intervalos de tiempo diversos (de tres hasta treinta minutos) y además predecible. En general además poseen buena iluminación, ventilación y temperatura ${ }^{9}$, aspectos mucho menos regulados en los buses.

Se da además, un fuerte contraste entre el interior de los vagones y sus respectivos andenes y estaciones (tanto de Metro como de Metrotren). Los andenes, pasillos y escaleras, son lugares de alto tránsito y, en general, de tránsito acelerado. No se observó lectura en ellos. Por otro lado, los lugares destinados eminentemente a las esperas dentro de las estaciones, tampoco albergan lectura de ningún tipo. En las zonas de espera, se encuentran personas, principalmente jóvenes y adultos jóvenes (menores de 40 años), de ambos sexos, detenidos, sentados o de pie, concentrados en sus computadores portátiles y celulares, trabajando a veces, pero principalmente jugando juegos en Internet, revisando redes sociales y utilizando softwares de mensajería. Estas zonas son comúnmente señaladas como zonas de acceso gratuito a conexión de Internet inalámbrico (WiFi). Con ello y la disposición de asientos y pequeñas mesas de apoyo, las actividades a realizar en ese espacio quedan bastante restringidas. A la vez, se emplazan en medio de espacios de alto tránsito, con mala ventilación y techos altos, todas condiciones que, como comentábamos antes, no facilitan el desarrollo de prácticas como la lectura de ocio. Por cierto, se dirá, muchas de las actividades basadas en conexiones de Internet son actividades de lectura. Sin embargo, nuestra interpretación no encuentra ninguna posibilidad de sumar las actividades hechas en el marco de las telecomunicaciones como una práctica de lectura.

Un tema interesante es que la lectura, no obstante, busca ambientes públicos donde la escala del entorno sea adecuada y donde la ventilación ayude; puede defenderse en lugares donde las condiciones son incómodas, hay escasa ventilación y hacinamiento. El ejemplo más claro es el vagón del Metro o del Metrotrén en horas punta, donde la enorme cantidad de viajeros obstaculiza las posibilidades de lectura, no obstante ella acontece de igual modo. De alguna manera, la aparición del rincón (del vagón) o una tolerable

9. No obstante es frecuente también que estos sistemas de ventilación sufran desperfectos, como sucedió durante las observaciones en el marco de esta investigación. 
incomodidad en medio del hacinamiento, logra que la lectura se realice mientras se satisfaga la otra condición ya mencionada: un entorno menos estimulante, menos estresante y donde la condición "de cacería" ha dado paso a una actividad en el "reposo" de la mera estancia. Bajo estas condiciones, incluso el tren lleno puede implicar alguna forma de intimidad, pues el "muro humano" puede otorgar la confianza mínima para imbuirse en el libro, para entregarse, concentrarse, sin estar alerta al espacio exterior a él.

\section{e) El café}

La ciudad letrada, que emerge a fines del siglo XIX en Europa y a comienzos del siglo XX se proyecta en diversas urbes, tuvo una institución central que parece ser la forma espacial que sintetiza la discusión (antes regulada por las normas del poder) en los salones con el arrebato iconoclasta del bar bohemio. Se trata del café (la cafetería). El conocimiento y sus dinámicas encuentran en el café un espacio fundamental. Muchas corrientes intelectuales nacieron o consolidaron sus procesos creativos en el marco de este espacio de discusión y elaboración (insigne es el Círculo de Viena, pero incontables son las corrientes literarias asociadas al café o los escritos, como Hemingway, que escribían en ellos). El café ha sido siempre un lugar donde no solo la discusión es relevante, sino además la opción de encontrar la diversión y el placer en los juegos de salón o en la lectura. En ninguna metrópoli es extraño ver a alguien que ingresa a un café con un libro en la mano, aun cuando esta escena se ha complementado hoy con los computadores portátiles y tabletas digitales.

Nuestras observaciones en cafeterías, sin embargo, nos depararon resultados muy negativos para la lectura. Se puede informar que en las muchas horas de observación en cafés, prácticamente no encontramos lectura en ellos. Más difícil de interpretar como dato: nos encontramos en muchas ocasiones con personas con libros sobre la mesa que nunca fueron leídos. Nuestra primera interpretación se dirigió a la posibilidad de una conducta "aspiracional" en términos de prestigio. Sin embargo, ello no cuadraría con las observaciones hechas en otras dimensiones (por ejemplo, en hogares) donde los libros se esconden incluso cuando existen y no son usados para prestigiar el hogar (incluso se guardan en el clóset). Dado ello, bosquejamos una segunda opción: que el café sea formalmente un lugar agradable para leer, pero que de alguna manera en la práctica haya dejado de serlo. Esta tesis tiene cierto fundamento, aun cuando sobre este punto es posible que se requiera más trabajo en el futuro.

El café contemporáneo ha sumado a su instalación un par de características nuevas que lo hace sustancialmente diferente a los anteriores. En ellos hay constante música ambiental o televisores con emisiones sonoras que a veces superan los $60 \mathrm{u} 80$ decibelios, constituyéndose en fuentes contaminantes constantes. Diversas regulaciones urbanas están contemplando evitar que en estos lugares se superen los 75 decibelios como ruido total, es decir, como suma del ruido de las fuentes fijas (música o televisión) más las conversaciones entre las personas. Pues bien, en lugares como estos, con una base de ruido importante, las personas deben conversar a un volumen más alto que el de la 
música, para escucharse entre sí. El resultado es una gran multiplicación de la contaminación acústica y un estrés permanente. Estas condiciones hacen muy difícil una lectura concentrada y prolongada. Por tanto, los cafés han sido invadidos por el ruido urbano y han dejado de ser un espacio de lectura viable.

\section{MATERIAL DE LECTURA EN ESPACIOS PÚBLICOS}

Los textos y documentos de lectura en espacios públicos, como comentábamos anteriormente, son principalmente relacionados a la lectura obligatoria. Documentos de trabajo, apuntes escolares o universitarios, textos de capacitación laboral, exámenes, y el ocasional folleto informativo, son algunos de los más comunes. Sin embargo, respecto a la lectura de ocio, encontramos al menos dos protagonistas:

\section{El libro}

Un lugar especial, aunque no el más frecuente, es el de los libros en los espacios públicos. Los libros demandan mayor concentración, mayor compromiso y entrega por parte de quien lee, a tal punto que muchas veces el libro parece llevar el ritmo de la lectura y no el lector o la lectora. Suele, además, requerir su espacio, en bolsos, carteras, mochilas o maletines.

En general, los libros que se ganan ese espacio, que le ganan al tránsito, a las intervenciones visuales, a la música y a los celulares, son las novelas de misterio. Novelas cuyo contenido se centra en los acontecimientos, de prosa ágil, llenas de personajes, que logran fundamentalmente entretener la atención del lector en espacios públicos.

Por otra parte, al aparecer libros en el espacio público, aparece también la diferencia, la estratificación. La transparencia de este carácter diferenciador del libro fue mayor en las observaciones realizadas en los vagones de la Línea 1 del Metro. En las estaciones del sector oriente, los libros eran textos especializados; novelas, filosofía, gestión, organización de empresas, marketing, etc. Mientras que hacia el poniente, disminuye la cantidad de libros y sus contenidos se hacen menos especializados: best-sellers y revistas principalmente. Como nota general, la lectura de poesía es nula en los espacios públicos.

Un fenómeno no masivo pero sí recurrente, es la exhibición de los libros, cosa que no sucede con el diario ni con las revistas. El libro a veces tiene solamente visibilidad, en vez de ser leído. Es recurrente sobre todo en cafeterías, pero también en algunos vagones de metro, encontrar personas cargando un libro, o dejándolo sobre la mesa simplemente. Conductas como estas indican quizás el vínculo que el libro aún posee con la marca de una práctica valorable y prestigiosa todavía.

Finalmente, los libros que tienen un lugar frecuente dentro de los espacios públicos son los de contenidos religioso, misticismo y esoterismo. En general, la lectura de textos como la Biblia, el Viejo y Nuevo Testamento, se da en lectores adultos y adultos mayores, de género masculino. Mientras que la lectura de textos New Age, 
de misticismo alternativo y de esoterismo es más frecuente en mujeres mayores de 30 años.

Los nuevos soportes de lectura, en dispositivos electrónicos de diferentes marcas y estilos, que se plantean como facilitadores de la lectura en espacios públicos, sobre todo en el transporte público, como ebooks y Kindles, no se utilizan. Otros dispositivos, como los celulares y reproductores de música sí son tremendamente ubicuos, pero ninguno se utiliza para leer. Asimismo los computadores portátiles en sus diferentes modelos, se encuentran en diferentes espacios como cafés, estaciones de metro y bibliotecas, pero se utilizan principalmente para elaborar documentos, trabajar en línea, estudiar y/o conectarse a redes sociales.

\section{El diario}

Principalmente periódicos de formato mediano, publicaciones de distribución gratuita y algunas revistas de variedad. Este tipo de documentos, de fácil manipulación, plegable, de contenidos contingentes y breves, son el material de los lectores más ubicuos de espacios públicos, que son muy variados, hombres, mujeres, jóvenes y adultos, aunque se aprecia también una mayoría de personas adultas, de tercera edad, y de sexo masculino. Estas lectoras y lectores son quienes forman fila a la entrada de las estaciones de metro para obtener las publicaciones de distribución gratuita. Se disponen a leer en escaños, en plazas y parques, esquinas, paraderos, buses, y al interior de vagones de metro.

Se encuentran también en bibliotecas, pasando el rato, incluso más de una hora, leyendo concentradamente de cabo a cabo los textos más variados que se encuentran en su interior. Por otra parte esta lectura parece ser transversal a comunas y niveles socioeconómicos. Es una lectura laxa, que puede ser concentrada o distraída, con frecuentes interrupciones o ninguna.

En paralelo al lugar de los dispositivos de telefonía móvil —que son el principal objeto de atención en espacios públicos, como veremos en detalle más adelante-, el diario es el objeto de quienes no usan estos dispositivos, ya sea por no poseerlos o por darle otro uso. En este sentido, si bien el diario no excluye drásticamente niveles socioeconómicos ni rangos etarios, sí se presenta con mayor frecuencia en manos de personas de la tercera edad y de nivel socioeconómico medio-bajo y bajo.

Otro paralelismo del diario con los dispositivos móviles, que es una de las pocas lecturas que se socializa. Sucede, aunque no frecuentemente, que personas almorzando o simplemente compartiendo un escaño, donde una hace referencia, o derechamente lee algún extracto del contenido del diario, a otra — práctica que se da hoy, casi exclusivamente en el acto de compartir imágenes, videos o mensajes de texto, desde la pantalla de un dispositivo electrónico personal a los ojos de un compañero o compañera de tránsito.

La lectura del diario se ajusta perfectamente al uso del espacio público que hemos definido anteriormente; es una lectura que no demanda protagonismo en sí. Se despliega, como pasatiempo cuando no hay nada que hacer, y, consecuentemente, se repliega, y desecha incluso, apenas surge alguna otra cosa, o bien agota su propio contenido. 


\section{Dispositivos tecnológicos personales}

Como hemos adelantado, la lectura en los espacios públicos convive y compite con una serie de otras conductas, que hemos denominado no-actividades. Si bien es sabida la masividad que han alcanzado prácticas asociadas a la disponibilidad de tecnología móvil, tanto en los espacios públicos como privados, examinaremos su alcance y magnitud en relación a espacios de convivencia con la lectura.

La conducta más frecuente en todos los espacios públicos observados, después de "hacer nada" — es decir, transitar o esperar solamente, sin actividad complementariaes manipular algún dispositivo electrónico portátil. Dispositivos de telefonía móvil, en sus diferentes tipos, marcas y modelos, son los principales captadores de atención de las personas, luego del entorno publicitario que opera como fondo permanente en la mayoría de los casos.

Ahora bien, cabe notar que las personas realizando estas conductas son jóvenes y adultos, menores de 60 años en general, todas y todos de nivel socioeconómico alto, medio y medio-bajo, mientras que se hacen cada vez menos frecuentes entre las personas de la tercera edad y de nivel socioeconómico bajo.

Asimismo en plazas, cafés y centros comerciales, en casi todos los espacios de espera, se puede contar con que la mayoría de las personas esté concentrada en sus notebooks, smartphones, iPads, y celulares más sencillos. El uso de estos dispositivos es generalmente individual, sin embargo también se da en grupos de personas, conocidas entre sí, donde cada uno está concentrado en su aparato personal, y de vez en cuando comparte alguna referencia al grupo, situación que no ocurre con la lectura.

En los lugares característicos de la lectura obligatoria, como las bibliotecas, estos dispositivos son la principal interrupción del estudio o trabajo. En intervalos de incluso 5 y 10 minutos, la lectura se ve intervenida por el chequeo de algún dispositivo móvil. Asimismo, se realizan pausas prolongadas de la actividad principal, en las que se dedica tiempo de alta concentración al dispositivo. A veces se escucha música mientras se lee. En vagones y en bibliotecas los audífonos son un accesorio recurrente.

\section{Salas de espera}

Considerando el carácter intersticial de la lectura en espacios públicos, las salas de esperas parecen reunir importantes condiciones que la podrían facilitar: asientos y sillones, sombra, tiempo, iluminación, etc. Sin embargo en la mayoría de estos lugares la lectura no sucede.

A diferencia de otros espacios consignados al consumo, las salas de esperas son espacios en general más sobrios. Relativamente silenciosos, limpios, con afiches informativos, algunas pantallas con un programa de televisión abierta o videos relacionados a la institución, y filas de personas de pie o sentadas, esperando su turno.

En las salas de espera, y en general de atención a personas, en casas comerciales y bancos, las esperas pueden ser bastante largas, más de 20 minutos esperando es frecuente. Las actividades de quienes esperan sin embargo nunca incluyen la lectura, salvo la 
revisión de documentos relacionados con el trámite que esperan realizar. En la mayoría de los casos la espera se acompaña de la revisión frecuente del dispositivo móvil, pero no concentrada ni prolongada. Las personas a pesar de estar esperando, se ven inquietas, ansiosas, preocupadas, alerta.

Algo parecido sucede en los espacios de tránsito o de alto flujo de personas, como en los pasillos y halls de las estaciones de metro y tren (a diferencia de lo que sucede en el interior de los vagones como revisamos), y en los paraderos de buses por ejemplo, donde a pesar de estar en un tiempo "muerto", es decir un tiempo obligado de espera, la actitud de alerta se mantiene y por ende ninguna lectura parece posible. Los celulares y reproductores de música de todas maneras siguen ofreciendo una distracción que se ajusta a la volatilidad de la atención en estos espacios, pero aun así no son tan usados como en otros espacios públicos.

En las esperas de hospitales el entorno es menos silencioso y limpio. El flujo de personas a su vez es menos ordenado: personas esperando de pie, otros sentados, durante horas, mientras personal del recinto pasa caminando aceleradamente entremedio. La iluminación y las condiciones de ventilación no son las mejores. Ruidos de llantos de niños e infantes, que se encuentran en consulta o que acompañan al consultante.

En este contexto, si bien la preocupación es la actitud dominante, la alerta tiende a ceder al cansancio, a la eternidad de la espera, y entonces sí vemos que la proporción de lectura aumenta, no de libros, pero sí de periódicos, y disminuye la del uso de dispositivos móviles. Existe además en estas esperas menos usuarios de estos dispositivos en general, más personas adultas-mayores y de nivel socioeconómico bajo. De todas maneras, los principales materiales entre manos siguen siendo los objetos de preocupación de ese espacio, exámenes y papeles de antecedentes.

La lectura es impertinente en los espacios de alerta, o de cacería si se quiere. Aquí las personas están atentas a lo que sucederá, no están en condiciones de distraerse de ello, ni siquiera con los dispositivos electrónicos — que lo logran con la mayor eficacia en todos los otros espacios públicos-y por supuesto tampoco con la lectura.

\section{Lectura y consumo en espacios públicos}

Muchos de los espacios públicos son a la vez espacios orientados directamente al consumo. Algunos de ellos, además, son los más concurridos, como casas comerciales, cafés y centros comerciales. Por otro lado, estos lugares suelen ofrecer espacios de espera, o de apostamiento, en tanto no solo reciben alto flujo sino que las personas suelen realizar permanencias prolongadas allí. Por estas razones, y considerando la presencia de lectura en otros espacios públicos, menos acondicionados, se podía suponer la ocurrencia de lectura de espera al menos, en alguno de estos espacios. No obstante, la lectura es inexistente.

Los centros comerciales, o malls, en general se plantean no solo como un conjunto de tiendas y restaurantes sino que también como un lugar que responde a una multitud de necesidades, incluida la salud y el esparcimiento. Así, los malls ofrecen una tremenda 
variedad de servicios y eventos culturales. Cines, teatros, salas de conciertos, pequeñas plazas y bulevares, escenarios al aire libre, juegos para niños, bibliotecas, y centros de atención médica, son algunas de las ofertas frecuentes de estos lugares. Se cuenta por ende con los momentos y los espacios para leer, sin embargo, en ninguno de estos lugares se desarrolla la lectura, de ningún tipo. No se maneja ningún tipo de documento escrito (más allá de la lectura de imágenes y textos publicitarios que están en exhibición, como parte del entorno), ni diarios, ni revistas, ni libros, ni folletos, ni volantes, nada.

Hemos revisado ya las condiciones adversas para la lectura en los espacios públicos, cuando su orientación predominante es la publicitaria, que desde luego, poseen también estos espacios comerciales. En este sentido no es extraño que dicho carácter sea más pronunciado en estos lugares cuya principal función es promover el consumo por parte de sus usuarios. La cantidad de estímulos visuales y audiovisuales sin duda aumentan la fuerza con la que se hace la invitación a consumir productos, llenando todos los espacios de la atención, y por supuesto que eso tiene un tremendo impacto en la disponibilidad de espacios para la lectura.

Las conductas de las personas en estos lugares son comprar y consumir productos, conversar, concentrarse en sus dispositivos electrónicos móviles, y simplemente descansar sin hacer nada. Sin embargo no deja de llamar la atención que incluso en los espacios destinados a la lectura como las bibliotecas y librerías en el interior de estos complejos, no se observa lectura. "Vitrineos" esporádicos, y sentarse a descansar del "vitrineo" de las tiendas, son los principales usos que se le dan estos espacios.

Algo similar sucede en los cafés. A pesar de ofrecer ciertas condiciones escasas en los espacios públicos, que podrían facilitar la lectura (como mesas, sillas, sillones, protección del sol, luz adecuada y buena ventilación) esta no se realiza allí. Cafeterías y salones de té, cerca de librerías, tanto dentro de centros comerciales como en calles de Providencia y Santiago Centro, no son escenarios de lectura en espacios públicos. Incluso en el caso de cafés que se plantean decididamente como espacios de lectura (como los cafés literarios de la Municipalidad de Providencia), son utilizados como zonas de trabajo, escritorios y extensiones de la oficina, donde la mayoría de las personas utiliza un computador portátil y textos manuscritos o documentos de trabajo.

La lectura recreativa se indica, en cambio, con la exhibición de algunos diarios, libros y revistas, dejados sobre la mesa, mientras se consumen cafés, jugos, se fuman cigarros y se chequea el dispositivo móvil constantemente, incluso en grupos como vimos anteriormente. Llama la atención la ausencia de lectura en estos lugares, sobre todo por su cercanía a librerías y el hecho de que el público asistente en varios casos porte material de lectura.

Por otro lado, en general estos lugares se emplazan, si no en centros comerciales, en calles y sectores de alto comercio, siendo funcionales a ese carácter principalmente. Una pausa entre compras o "vitrineo", o bien una extensión del lugar de trabajo.

En suma, la lectura en los espacios públicos parece estar reñida con el consumo. En términos concretos, en los espacios orientados eminentemente al consumo, no hay lectura. Y junto con ello podemos agregar que la lectura de ocio es excluida también de los espacios de productividad, que entendemos es una práctica también orientada 
generalmente al consumo. Un caso ejemplar de este fenómeno es el de la escasez de la lectura ociosa, justamente en bibliotecas.

\section{OFERTA DE MATERIAL DE LECTURA EN ESPACIOS PÚBLICOS}

La oferta de material de lectura en espacios públicos es escasa. Sin embargo existen servicios, sobre todo bibliotecarios, que, como hemos mencionado ya, no se utilizan con toda la frecuencia para la que están dispuestos. La oferta de mayor visibilidad en los espacios públicos es la siguiente:

a) Distribución gratuita de periódicos en algunos accesos y salidas del Metro: como hemos mencionado anteriormente, el periódico es uno de las lecturas más comunes en los espacios públicos, y en acuerdo con ello, los periódicos de distribución gratuita despiertan gran interés en los transeúntes.

b) Bibliotecas al interior de estaciones de Metro: su emplazamiento en pasillos y halls de alto tránsito de algunas estaciones del Metro le dan bastante visibilidad a este servicio, sin embargo es raro encontrar personas utilizándolo. Su catálogo es variado, principalmente de ficción y con textos relativamente actuales.

c) Librerías: las de mayor visibilidad y flujo son las concentradas en principalmente tres o cuatro sectores de la ciudad, en su mayoría en las comunas de Providencia y Santiago Centro ${ }^{10}$. Estas librerías en general se ubican en sectores de comercio y cafés, y ofrecen varios tipos de literatura, algunas centradas en la de moda, otras centradas en literatura especializada, en humanidades y artes visuales mayormente, con catálogos relativamente actualizados. Algunas ofrecen espacios cómodos para la lectura, pero rara vez son utilizados. Los precios de venta son en promedio de $\$ 40.000$ aprox., y también ofrecen algunas colecciones de bolsillo y ediciones menos costosas. Son las librerías con el mayor flujo de clientes.

d) Librerías de compra y venta de libros usados: por lo general se concentran en dos o tres corredores y galerías. Las más visibles y concurridas son las de la calle San Diego y Providencia con Manuel Montt. Ofrecen libros de estudio principalmente, para escolares, estudiantes secundarios, estudiantes universitarios y textos especializados de literatura y de colección. Los catálogos son más bien clásicos, poco actualizados, y sus precios de venta promedian los $\$ 15.000$ aprox. Son librerías de bajo flujo de clientes en general.

e) Libros de feria: en las colas de la ferias de barrio, en ferias de parques y ferias en circuitos turísticos, se emplazan puestos de venta de libros usados. En general ofrecen literatura desactualizada y especializada, a precios bajos, promediando los $\$ 5.000$. No obstante son puntos de bajo flujo de clientes en general.

10. Esta zona, aunque pequeña en sus kilómetros cuadrados de superficie, es con mucha diferencia la zona con mayor oferta de librerías del país. Se calcula que la mayor parte de las ventas de libros se dan en un espacio que concentra dos o tres comunas del país. 
En general, la oferta de libros no se condice con la lectura que se ve en los espacios públicos. Justamente los libros de menor precio son los que no le interesan a los lectores en espacios públicos. Cabe destacar, no obstante, los casos de venta ilegal de libros en la calle, que en general y por la naturaleza del fenómeno, se orienta a los libros "de moda", como sagas y best-sellers en general. Sin embargo este material de lectura no se lee en los espacios públicos, sino que más bien en los hogares.

Por otro lado existen iniciativas relativamente nuevas como Biblioplaza (Santiago Centro) y Café al Aire Libro (Providencia), que intentan facilitar la lectura en plazas y parques, y que, si bien aún no tienen un alto flujo y visibilidad, son iniciativas pioneras en captar al público lector en estos espacios.

\section{INTERVENCIONES ORIENTADAS A LA LECTURA EN ESPACIOS PÚBLICOS}

Se detectaron en nuestras revisiones diversas intervenciones, ya sea en el marco de acciones particulares o políticas públicas, para intentar potenciar la lectura en espacios públicos. El equipo realizó una recopilación lo más exhaustiva posible de estas iniciativas. No es relevante dicho listado para este documento, pero sí comprender sus orientaciones principales y posibles limitaciones. Nuestra revisión no solo evaluó actividades asociadas al estímulo de la lectura, sino que además fueron consideradas las actividades complementarias a la lectura, como la escritura, ilustración, declamación. Se estimula el gusto por la literatura en sus distintas versiones. La lógica es que quien gusta de escribir, de hablar de literatura, del teatro, se motivará también a leer.

Nuestra revisión detectó que las principales fórmulas observadas son aquellas asociadas a facilitar el acceso a libros a través de dos mecanismos: acercar los libros y periódicos, en primer lugar; y facilitar el trámite de préstamo, como corolario. Gran parte de las iniciativas son de extensión bibliotecaria, es decir, se trata de poner a disposición títulos en espacios donde tradicionalmente no los hay (balnearios, playas, pequeños pueblos y zonas rurales aisladas, cárceles, hospitales, escuelas), como son los casos de bibliomóviles, biblioplaya, bibliotecas viva en centros comerciales, donación de libros a cárceles, instalación de pequeñas bibliotecas comunitarias. Respecto al segundo criterio en iniciativas como Café Aire Libro o Biblioplaya de Chiloé los vecinos están exentos de registrarse para tomar y leer ejemplares, mientras se encuentran en el parque. La lógica es que si las personas tienen facilidades para acceder a libros, se motivarán a leerlos. Probablemente el fundamento es que el principal freno para acceder a los libros es la dificultad para acercarse a ellos, por costo o por la hostilidad posible de ciertos entornos cargados de otras significaciones o de escasa centralidad, como bibliotecas públicas. La premisa es discutible, pero indudablemente para el consumo de bienes suntuarios siempre habrá un margen de certeza en este tipo de observación.

Se ve una innovación en cuanto al criterio de asociación entre la biblioteca como espacio de lectura y la biblioteca como lugar donde se pone a disposición libros, diarios y revistas. A diferencia de épocas pasadas hoy predominan y se fomentan este último tipo de intervenciones, lo que se condice con nuestras observaciones, que muestran que los 
espacios de las bibliotecas y cafés son utilizados principalmente como salas de estudio y encuentro y no como lugares donde ejercer la práctica lectora estrictamente ociosa.

Aunque hay muchas actividades de fomento a la lectura en regiones, las iniciativas más innovadoras parecen estar concentradas en la Región Metropolitana, siendo predominantes fuera de Santiago las bibliotecas públicas tradicionales, los bibliomóviles y los cuentacuentos.

La principal deficiencia del tipo de intervenciones que se ejecutan reside en la escasa conciencia respecto a los principios que fuimos desglosando con nuestra investigación. La lectura en la ciudad sobrevive cuando el ambiente, la ecología, le resulta viable para su desarrollo. No hay lectura si hay un ambiente de estrés y exigencias, no la hay cuando hay sobreestimulación (ruido e imágenes), no la hay cuando hay riesgo o un ambiente "de cacería" donde las exigencias de concentración con el entorno son significativas. No la hay en medio de un mal clima en un parque o plaza, pero tampoco cuando se carece de sombra.

Nuestros estudios en general nos muestran que la lectura en espacios públicos parece tener más posibilidades que lo que puede darse en el hogar o la oficina, donde su debilitamiento resulta ser muy significativo. Sin embargo, incluso asumiendo esta conclusión, debe señalarse que la lectura en espacios públicos está fuertemente presionada por un entorno inadecuado y muchas veces se encuentra retrocediendo. Es convicción de los autores que modificar estas condiciones requiere concretamente una clara perspectiva en el diseño de las ciudades: es el urbanismo una de las claves de la lectura en el futuro. Pensar los lugares como habitables por lectores es crucial. Si se diseñan vagones de Metro atiborrados con siete personas por metro cuadrado, aun cuando haya lectores que logran leer en el hacinamiento, se está presionando esta práctica a la muerte en los vagones, al menos en las horas punta (que naturalmente son las masivas). Si los parques no son diseñados en escalas adecuadas, con las sombras necesarias, cuando los espacios no invitan a la reunión y la comunidad, la lectura decrece. No en vano la lectura colectiva aparece cuando hay experiencias comunitarias relevantes, como en la Plaza de Armas de Santiago con el club de ajedrez que en ella se cobija. La ciudad como institución del desarrollo de la cultura necesita un correlato arquitectónico. Y, siendo así, crecerá la lectura. 